\title{
A genetic locus and gene expression patterns associated with the priming effect on lettuce seed germination at elevated temperatures
}

\author{
Andrés R. Schwember • Kent J. Bradford
}

Received: 4 September 2009/Accepted: 16 December 2009/Published online: 3 January 2010

(C) The Author(s) 2010. This article is published with open access at Springerlink.com

\begin{abstract}
Seeds of most cultivated varieties of lettuce (Lactuca sativa $\mathrm{L}$.) fail to germinate at warm temperatures (i.e., above $25-30^{\circ} \mathrm{C}$ ). Seed priming (controlled hydration followed by drying) alleviates this thermoinhibition by increasing the maximum germination temperature. We conducted a quantitative trait locus (QTL) analysis of seed germination responses to priming using a recombinant inbred line (RIL) population derived from a cross between $L$. sativa cv. Salinas and $L$. serriola accession UC96US23. Priming significantly increased the maximum germination temperature of the RIL population, and a single major QTL was responsible for $47 \%$ of the phenotypic variation due to priming. This QTL collocated with Htg6.1, a major QTL from UC96US23 associated with high temperature germination capacity. Seeds of three near-isogenic lines (NILs) carrying an Htg6.1 introgression from UC96US23 in a Salinas genetic background exhibited synergistic increases in maximum germination temperature in response to priming. $L s N C E D 4$, a gene encoding a key enzyme (9-cis-epoxycarotinoid dioxygenase) in the abscisic acid biosynthetic pathway, maps precisely with Htg6.1. Expression of LsNCED4 after imbibition for $24 \mathrm{~h}$ at high temperature was greater in non-primed seeds of Salinas, of a second cultivar (Titan) and of NILs containing Htg6.1 compared to primed seeds of the same genotypes. In contrast, expression of genes encoding regulated enzymes in the gibberellin and ethylene biosynthetic pathways (LsGA3oxl and LsACSI,
\end{abstract}

Electronic supplementary material The online version of this article (doi:10.1007/s11103-009-9591-x) contains supplementary material, which is available to authorized users.

A. R. Schwember · K. J. Bradford ( $\square)$

Department of Plant Sciences, One Shields Ave., University

of California, Davis, CA 95616-8780, USA

e-mail: kjbradford@ucdavis.edu respectively) was enhanced by priming and suppressed by imbibition at elevated temperatures. Developmental and temperature regulation of hormonal biosynthetic pathways is associated with seed priming effects on germination temperature sensitivity.

Keywords Abscisic acid · Ethylene - Germination · Gibberellin · Priming $\cdot$ QTL $\cdot$ Thermoinhibition

\section{Introduction}

Seed priming is the controlled hydration of seeds to allow completion of the first steps in the germination process before the seeds are subsequently dried, distributed and sown (Bruggink 2004). To achieve this, seeds are partially hydrated to a water content where germination processes can begin, but radicle emergence does not occur (Heydecker and Coolbear 1977). Seed water content can be controlled by priming seeds in osmotic solutions (osmopriming) or by supplying only predetermined amounts of water to the seeds or limiting the imbibition time (hydropriming). Following the hydration period, seeds are subsequently dried to their original moisture content and stored or planted. In general, seed priming induces faster and more uniform germination over a broader temperature range when the primed seeds are subsequently planted (McDonald 2000). This practice is applied commercially in many crops to improve germination rate (speed), and particularly in lettuce (Lactuca sativa $\mathrm{L}$.) to alleviate thermoinhibition (failure of seeds to germinate when imbibed at warm temperatures) by increasing the maximum temperature at which germination will occur (Cantliffe et al. 1981; Valdes et al. 1985).

Little is known about the genetics of seed priming or the potential genes or mechanisms involved in increasing the 
maximum germination temperature of primed seeds. Soeda et al. (2005) found that a small but distinct group of seed maturation genes (i.e., late-embryogenesis abundant and storage compound-related genes) correlated to stress tolerance in primed seeds of Brassica oleracea. Those authors also discovered that a large group of genes was up-regulated during germination in water, but not during priming, representing genes that are specific to germination in water or are inhibited by low water potential. Gao et al. (1999) found that transcripts of two different aquaporins (BnPIPI and $B n \gamma$-TIP2) were present earlier during germination of primed canola (Brassica napus) seeds than of non-primed seeds, although priming itself induced only the expression of BnPIP1. They proposed that BnPIP1 is related to the water transportation required for enzymatic metabolism of storage nutrients at the early stages of canola seed germination while $B n \gamma-T I P 2$ expression is related to cell growth associated with radicle protrusion. In Arabidopsis, Gallardo et al. (2001) identified three priming-associated proteins (i.e., one tubulin subunit and two 12S-cruciferin $\beta$-subunits) whose abundance or solubility increased during priming treatments. An increase in 11-S globulins associated with storage protein mobilization has been reported in primed sugar beet (Beta vulgaris) seeds (Job et al. 1997), whereas tubulin subunits are presumably involved in reactivation of cell cycle activity during priming (de Castro et al. 2000). In addition, two low-molecular weight heat shock proteins specifically increased during osmopriming (Gallardo et al. 2001). Ligterink et al. (2007) identified a number of genes in tomato (Solanum lycopersicum) whose expression is associated either positively or negatively with responses to priming, but their modes of action have not been determined. Nascimento et al. (2001) showed that endo- $\beta$-mannanase activity increased in the lettuce endosperm during priming and before or coincident with radicle emergence in non-primed seeds, and suggested that it may be involved in weakening of the micropylar endosperm to allow radicle emergence. In addition, seeds of a thermotolerant lettuce variety (Everglades) exhibited much higher endo- $\beta$-mannanase activity than did seeds of a thermosensitive variety (Dark Green Boston). Similarly, Dutta et al. (1997) reported that activity of a cell wall-bound endo- $\beta$-mannanase extracted from lettuce endosperms prior to radicle emergence was reduced by imbibition at high temperature. However, others have reported that endo$\beta$-mannanase is present only in the lateral endosperm after radicle emergence in lettuce seeds (Halmer et al. 1975; Nonogaki and Morohashi 1999). Thus, the specific genetic or molecular mechanisms underlying the increase in the maximum germination temperature by seed priming remain unclear.

Abscisic acid (ABA), gibberellins (GA), and ethylene have been implicated in regulating germination and dormancy in lettuce seeds in relation to light and temperature, with ABA inhibiting and GA and ethylene promoting germination (Cantliffe et al. 2000; Kucera et al. 2005). A key regulated step in ABA biosynthesis is catalyzed by 9-cis-epoxycarotenoid dioxygenase (NCED), which cleaves 9-cis-xanthophyll to xanthoxin, a precursor of ABA (Tan et al. 2003; Lefebvre et al. 2006). Our group previously identified a quantitative trait locus (QTL) for high temperature germination (Htg6.1) conferred by L. serriola accession UC96US23, one parent of a recombinant inbred line (RIL) population derived from a cross with $L$. sativa cv. Salinas (Argyris et al. 2005, 2008b). One member of the NCED gene family in lettuce ( $L S N C E D 4)$ is regulated by photochrome, being induced by far-red light and repressed by red light (Sawada et al. 2008a). LsNCED4 maps to the same genetic region as Htg6.1 and is induced by imbibition at high temperature in genotypes susceptible to thermoinhibition, resulting in elevated seed ABA content (Argyris et al. 2008a). The gene encoding an enzyme that catalyzes the last step in the formation of active $\mathrm{GA}_{1}$, GA 3- $\beta$-hydroxylase ( $L s G A 3 o x l$, formerly called $L s 3 h l$ ) is a control point in the regulation of GA biosynthesis by light in lettuce seeds (Toyomasu et al. 1998; Sawada et al. 2008b). Expression of LsGA3oxl increases during imbibition in the light prior to radicle emergence, but is repressed in lettuce seeds imbibed at high temperature (Argyris et al. 2008a), possibly through the action of ABA (Sawada et al. 2008b; Toh et al. 2008). Conversely, both GA-dependent and GA-independent mechanisms can influence ABA metabolism in lettuce seeds (Sawada et al. 2008a). Ethylene production by lettuce seeds is correlated positively with the ability to germinate at high temperature (Saini et al. 1986, 1989; Nascimento et al. 2000; Kozarewa et al. 2006). Expression of the 1-aminocyclopropane carboxylate (ACC) synthase gene (LsACSI), which encodes the enzyme catalyzing the rate-limiting step of ethylene biosynthesis, is suppressed in lettuce seeds by imbibition at high temperatures (Argyris et al. 2008a). Thus, imbibition of lettuce seeds at high temperature results in promotion of ABA biosynthesis and repression of GA and ethylene biosynthesis, leading to inhibition of germination. However, it is not known whether seed priming alleviates thermoinhibition by reducing the expression of LsNCED4, resulting in decreased synthesis of $\mathrm{ABA}$, or by promoting the expression of LsGA3oxl or LsACSI, increasing GA and ethylene synthesis, either of which may enhance the germination of lettuce seeds at high temperatures.

The objectives of this study were to identify genetic loci associated with the alleviation of thermoinhibition of lettuce seeds due to priming and to determine whether the expression of genes associated with $\mathrm{ABA}, \mathrm{GA}$ and ethylene biosynthesis during seed imbibition were altered by priming. We conducted a QTL analysis of the ability of priming 
to increase the maximum temperature of lettuce seed germination. In addition, near-isogenic lines (NILs) derived by introgressing a genomic region containing a QTL associated with the capacity to germinate at high temperature (Htg6.1) into the Salinas genetic background were analyzed for their responses to priming. Expression of $L s N C E D 4, L s G A 3 o x I$ and LsACSI was assessed in relation to the effect of priming on the maximum temperature for germination. The results support key roles for suppression of LsNCED4 expression and for enhancement of LsGA3oxl and LSACS1 expression in the alleviation of thermoinhibition by seed priming.

\section{Materials and methods}

Genotypes and seeds

A recombinant inbred line (RIL) population derived from an interspecific cross between $L$. sativa cv. Salinas and $L$. serriola accession UC96US23 that has been analyzed previously for seed germination and quality traits was utilized (Argyris et al. 2005, 2008b). This lettuce mapping population was developed by Dr. Richard Michelmore's group at UC Davis (Truco et al. 2007). Near-isogenic lines (NILs) were developed by backcrossing a RIL carrying the UC96US23 allele at Htg6.1 into the recurrent parent Salinas (Argyris 2008). Three generations of backcrossing with marker-assisted selection followed by two selfing generations allowed the identification of NILs homozygous for an introgression containing Htg6.1 from UC96US23 but $>95 \%$ Salinas in the remaining genome (Argyris 2008). The size of the introgression varied among NIL lines, but represented roughly half of linkage group 6. In Figs. 4 and 6 , the sub-NILs pooled for each genotype were the following: NIL 2 lines homozygous for the Salinas (133, 144, 165,179 , and 190) or UC96US23 $(109,114,163,193$, and 198) allele; NIL 27 lines homozygous for the Salinas (105, $163,172,180$, and 249) or UC96US23 $(112,117,128,131$, and 143) allele; and NIL 86 lines homozygous for the Salinas $(183,187,188,192$, and 206) or UC96US23 allele (132, 133, 151, 159, and 169) (Argyris 2008). Seeds of both the RIL populations and the NIL families were produced in the field in Davis, California in 2006. A commercial lettuce cultivar (Titan) was a selection from and therefore has a very similar genetic background as Salinas; seeds were provided by Synergene Seed \& Technology, Inc., Salinas, CA.

Seed priming protocol

Seeds of the parent lines, 89 RILs, and 3 NILs were osmoprimed using a standard protocol (Heydecker et al.
1973; Tarquis and Bradford 1992) as follows: $1.2 \mathrm{~g}$ of seeds of each line was placed in an $8.8-\mathrm{cm}$ Petri dish and the seeds were primed over one blotter in $10 \mathrm{~mL}$ of water or $-1.25 \mathrm{MPa}$ solution of polyethylene glycol (PEG) 8000 for $48 \mathrm{~h}$ at $9^{\circ} \mathrm{C}$ under continuous fluorescent light. Seeds were then rinsed briefly with water and surface water was removed by suction in a Buchner funnel. Subsequently, seeds were rapidly dried for $2 \mathrm{~h}$ at $32^{\circ} \mathrm{C}$ and $25-30 \%$ relative humidity $(\mathrm{RH})$ in a ventilated oven, then were transferred to a chamber at $9^{\circ} \mathrm{C}$ and $30 \% \mathrm{RH}$ and equilibrated for at least 2 days to constant moisture content. Seeds were stored thereafter in the same condition. Titan seeds $(50 \mathrm{~g})$ were osmoprimed in $250 \mathrm{~mL}$ of aerated $-1.25 \mathrm{MPa}$ solution of PEG 8000 at $9^{\circ} \mathrm{C}$ under continuous fluorescent light for durations of 6,12, 24 and $48 \mathrm{~h}$. Subsequently, the same post-priming drying and storage conditions were employed as described above.

\section{Germination assays}

Tests for germination were conducted on filter papers moistened with $4 \mathrm{~mL}$ of $\mathrm{H}_{2} \mathrm{O}$ in $3.8-\mathrm{cm}$ diameter Petri dishes in constant temperature chambers or on a temperature gradient table with continuous fluorescent light. Total germination (radicle emergence) was scored 3 days after planting.

A thermogradient table was used to test germination at $1{ }^{\circ} \mathrm{C}$ increments across the following temperature ranges: for Salinas seeds, from 25 to $35^{\circ} \mathrm{C}$; for UC96US23 seeds, from 34 to $44^{\circ} \mathrm{C}$; and for the RIL and NIL populations, from 27 to $35^{\circ} \mathrm{C}$. In all these tests, two replicates of 25 seeds each were placed on two blotters wetted with $4 \mathrm{~mL}$ of distilled water in 3.8-cm Petri dishes and covered with tight-fitting lids. The percentage of radicle emergence was assessed $48 \mathrm{~h}$ after planting for the RILs and the NILs, and $72 \mathrm{~h}$ after planting for Salinas and UC96US23.

The germination percentages of control and primed seeds of the RIL population and of the sub-lines of NILs 2, 27 and 86 were transformed to probits to normalize variances in data distribution. Statistical analysis of the overall priming effect was conducted on the probit-transformed values using the General Linear Model of the SAS statistical program (SAS Institute Inc., Cary, NC, USA).

\section{QTL analyses}

For low resolution mapping, a set of 486 markers approximately $2-3 \mathrm{cM}$ apart on nine chromosomal linkage groups were chosen as the framework map for QTL analysis (Argyris et al. 2005). For QTL associated with increased germination at high temperature following priming, the differences between probit-transformed germination percentage values for control and primed seeds of 
each RIL were analyzed using composite interval mapping (CIM) in Windows QTL Cartographer V. 2.5. QTL were verified by 1,000 permutations of phenotypic data and declared significant $(P=0.05)$ above the permutated $\log$ likelihood ratio (LOD score) threshold of 3.2.

For high-resolution mapping, markers from a high density Affymetrix GeneChip ${ }^{\circledR}$ mapping array (van Leeuwen et al. 2007) were combined with the framework markers comprising linkage group 6 from the Lactuca integrated map (Truco et al. 2007). Sequence polymorphisms revealed by differential hybridization of DNA from 113 RILs hybridized in duplicate to the array were ordered using MadMapper (https://cgpdb.ucdavis.edu/XLinkage/MadMapper) (van Leeuwen et al. 2009). A marker was selected from each distinct genetic bin (unique recombinations between adjacent markers) covering linkage group 6 and these were entered into QTL Cartographer to identify relevant sets of genetic markers encompassing the QTL interval. These, plus the framework markers from the integrated map, were entered into JoinMap V 4.0 (Stam 1995) and the resulting maps with genetic distances were then reanalyzed in QTL Cartographer. A covariance analysis was performed to adjust the germination values for the effects of the Htg6.1 alleles (either Salinas or UC96US23). The differences between probit-transformed germination percentage values for control and primed seeds of each RIL were corrected by the allelic effects using a covariate regression analysis (using PROC REG and PROC GLM of SAS), and adjusted values were subsequently analyzed by QTL Cartographer and ANOVA.

\section{Gene expression analyses}

Total RNA was extracted from $0.5 \mathrm{~g}$ of whole Salinas seeds at 0,8 , and $24 \mathrm{~h}$ after imbibition at $32^{\circ} \mathrm{C}$ (Fig. 5), and from $0.5 \mathrm{~g}$ of whole Titan seeds primed for $0,6,12,24$, and $48 \mathrm{~h}$ followed by drying and after subsequent imbibition at $35^{\circ} \mathrm{C}$ (Fig. 7) using methods previously described (Cooley et al. 1999; Argyris et al. 2008a). In Fig. 6, multiple lines were pooled to randomize the genetic background at locations other than the introgression containing Htg6.1. Twenty seeds of each of $5 \mathrm{BC}_{3} \mathrm{~S}_{2}$ sub-NILs described above (100 seeds in total, which constituted one biological replicate) of NILs 27 and 86 were pooled by genotype at the Htg6.1 marker locus: Salinas alleles were pooled separately from UC96US23 alleles. Quantitative RT-PCR assays of gene expression were conducted using methods and normalization procedures described previously (Argyris et al. 2008a). The genes assayed in this study are LsNCED4, LsGA3oxl and LsACS1 along with $18 s 1, P P 2 A$, and $U B C 21$ for normalization; the accession and contig numbers and primer combinations used are shown in Supplemental Table SI of Argyris et al. (2008a).

\section{Results}

Priming increases the maximum germination temperature of lettuce seed

Priming seeds of Salinas and UC96US23 increased their germination at warm temperatures relative to the respective control (non-primed) seeds (Fig. 1). Before priming, over $95 \%$ of Salinas seeds germinated up to $27^{\circ} \mathrm{C}$, but only $2 \%$ germinated at $29^{\circ} \mathrm{C}$. In contrast, the primed seeds exhibited $>90 \%$ germination up to $30^{\circ} \mathrm{C}$, with a more gradual decline with increasing temperatures, reaching $0 \%$ at $35^{\circ} \mathrm{C}$. The median maximum temperature for germination $\left(T_{50}\right.$, or the temperature at which germination is reduced to $50 \%$ ) increased by $4^{\circ} \mathrm{C}$ due to priming. The maximum germination temperature of UC96US23 seeds also increased due to priming, but since the control seeds already germinated fully to $35^{\circ} \mathrm{C}$ and were not completely inhibited until $38^{\circ} \mathrm{C}$, the potential for increasing the maximum was limited (Fig. 1). Nonetheless, germination of the primed seeds remained greater than $90 \%$ as high as $37^{\circ} \mathrm{C}$, an increase of $1-2^{\circ} \mathrm{C}$ compared to the control UC96US23 seeds.

Priming effects on maximum germination temperature associate with a QTL

Seeds of 89 recombinant inbred lines (RILs) derived from a cross between Salinas and UC96US23 were left untreated (control) or primed and imbibed at temperatures between 27 and $35^{\circ} \mathrm{C}$ to determine their maximum germination temperatures. Priming increased the maximum germination temperature of about half of the RILs (Fig. 2). Statistical analyses conducted using ANOVA confirmed that priming

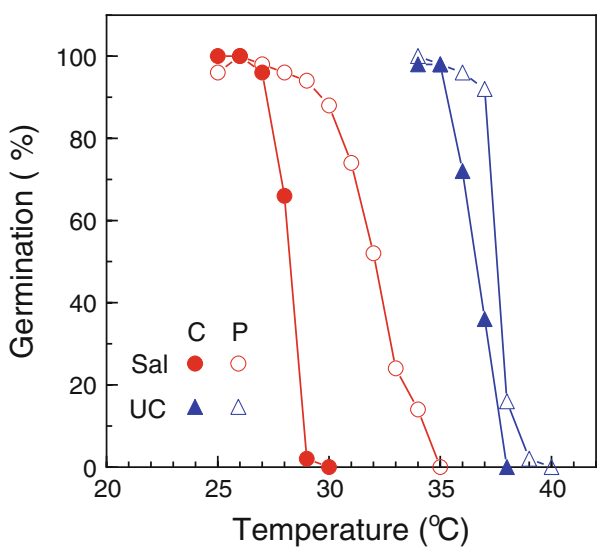

Fig. 1 Sensitivity of seed germination of Lactuca sativa cv. Salinas (Sal, circles) and L. serriola UC96US23 (UC, triangles) to temperature and priming (untreated, closed symbols; primed, open symbols). Seeds ( 25 in each of two replicates) were imbibed in Petri dishes at each temperature and radicle emergence was scored $72 \mathrm{~h}$ after planting 
Fig. 2 Temperature responses of germination of control (a) and primed (b) seeds of 89 recombinant inbred lines (RILs) at $27-35^{\circ} \mathrm{C}$. Two replicates of 25 seeds each were tested at each temperature on a gradient table, and radicle emergence was scored $48 \mathrm{~h}$ after planting. In both panels, RILs are ranked in order of increasing germination percentage of the primed seeds at the maximum temperature at which germination occurred

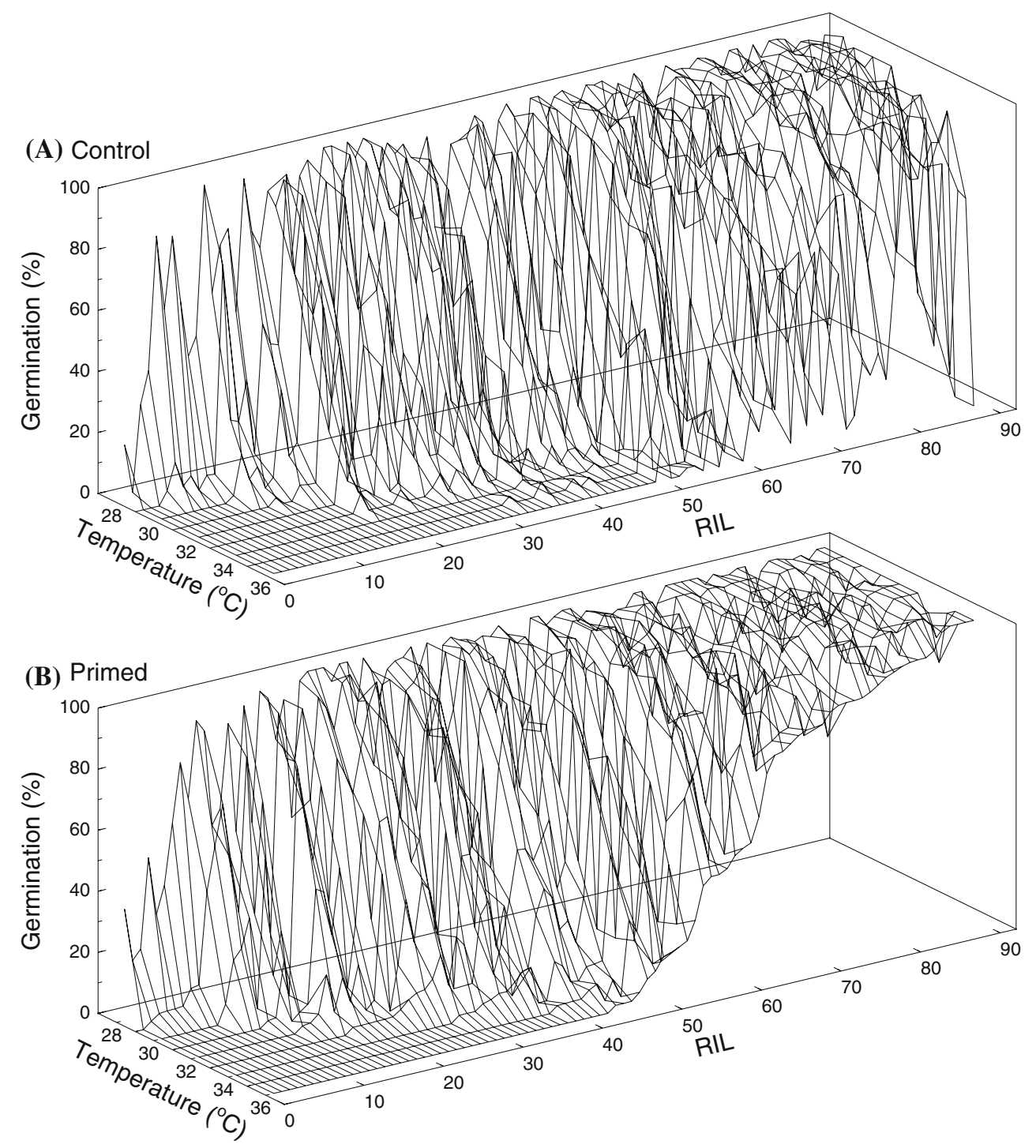

significantly increased germination of the RIL population $(P<0.0001)$ (Supplemental data, Table S1). For example, primed seeds overall exhibited $61.9 \%$ germination versus $49.7 \%$ for control seeds at $30^{\circ} \mathrm{C}$ and $31.5 \%$ versus $13.1 \%$ at $35^{\circ} \mathrm{C}$. In addition, a significant interaction among RILs, priming, and temperature was detected $(P<0.0001)$ (Table S1), confirming that RILs responded differently to priming and to temperature across the $27-35^{\circ} \mathrm{C}$ temperature gradient. Seeds of RILs that germinated better at warm temperatures also showed the largest increases in germination due to priming (Fig. 2).

To investigate the genetic basis of the germination increase by seed priming, QTL analyses were performed on the probit-transformed germination percentage data for control and primed seeds and for the increase in germination due to priming (probit of primed percentage minus probit of control percentage). Using low resolution mapping, a single significant QTL was identified on linkage group (chromosome) 6 that was responsible for $39.3 \%$ of the variance and was conferred by the UC96US23 allele at this locus (data not shown). This QTL collocated with one responsible for over $60 \%$ of the phenotypic variation in high temperature germination between the parent lines, provided also by the UC96US23 allele, termed Htg6.1 (Argyris et al. 2005, 2008b). High resolution mapping on linkage group 6 was subsequently conducted utilizing a high-density map based on sequence-based polymorphisms detected using a tiled microarray representing over 35,000 lettuce genes (van Leeuwen et al. 2009). Again, a single QTL was identified that was responsible for $46.9 \%$ of the variation in the increase in germination at $35^{\circ} \mathrm{C}$ due to priming (Fig. 3).This QTL again collocated precisely with the QTL for high temperature germination Htg6.1, and LsNCED4 mapped to the center of the QTL confidence interval (Fig. 3). Similar results were found using only the control or only the primed germination data (not shown). 
Fig. 3 High-resolution mapping of a QTL on chromosome 6 associated with the increase in maximum germination temperature due to priming when tested at $35^{\circ} \mathrm{C}$ using a RIL population derived from $L$. sativa cv. Salinas and L. serriola UC96US23. The LOD (log of odds) scores in the upper graph are significant above a value of 3.2 (horizontal line). The lower graph indicates which parent contributed the trait, with positive values indicating Salinas and negative values indicating UC96US23.

The QTL confidence interval spans the chromosomal region from 33 to $56 \mathrm{cM}$. The maximum QTL peak exhibits a 9.8 LOD score positioned at $43 \mathrm{cM}$, collocating with LsNCED4 at $43.5 \mathrm{cM}$

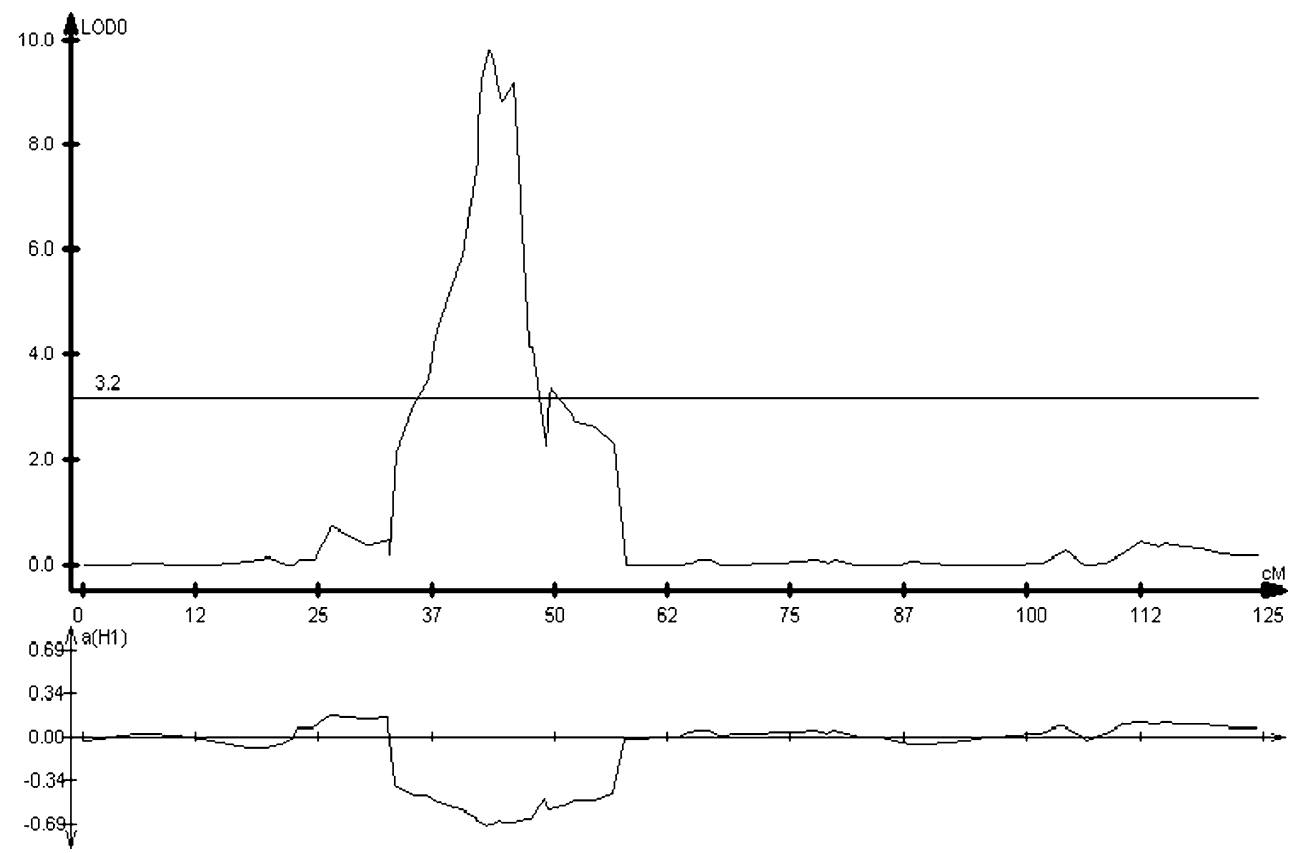

Further fine-mapping has reduced the Htg6.1 confidence interval to as little as $1 \mathrm{cM}$ in some seed production environments, and LsNCED4 remains centered in the Htg6.1 interval (Argyris et al., unpublished results). Thus, the Htg6.1 QTL that confers germination thermotolerance in this population is also associated with the increase in high temperature germination following priming.

As Htg6.1 had a large effect on maximum germination temperature in both primed and control seeds, it may be masking loci having smaller effects in the statistical analysis. We therefore conducted a covariate analysis to remove the effect of Htg6.1 and determine whether other QTL were present. Even after controlling for the effect of the Htg6.1 allele, the RIL $\times$ Treatment $\times$ Temperature interaction was highly significant, indicating that RILs still responded differently to priming across temperatures (Table S2). When germination values adjusted for the effect of the Htg6.1 allele across the entire population were analyzed only for control seeds, no QTL was detected, confirming that the covariate analysis had corrected for the effect of Htg6.1. However, QTL mapping using the primed seed data or the difference in germination between control and primed seeds identified the Htg6.1 locus as highly significant (LOD score 8.2, 26.1\% of remaining variation explained) as well as a second minor QTL on chromosome 5 that just exceeded the LOD score threshold (LOD score $3.5,11.3 \%$ of the remaining variation explained). However, the second QTL was not confirmed by high-resolution mapping $(\mathrm{LOD}=2.0$; data not shown). Thus, the UC96US23 Htg6.1 locus conditions a significant priming response that increases germination at high temperature beyond its effect in control seeds. We were unable to conclusively identify other QTL that might contribute to this effect.

Responses to priming of near-isogenic lines containing Salinas or UC96US23 alleles at Htg6.1

Marker-assisted backcrossing and selection were utilized to introgress a genomic region containing Htg6.1 from UC96US23 into a Salinas background and to develop NILs (Argyris et al. 2008b; Argyris 2008). Five $\mathrm{BC}_{3} \mathrm{~S}_{2} \mathrm{NIL}$ progeny lines derived from each of three NIL families (2, 27 and 86) were assessed to test whether this genomic region is specifically associated with differential responses to priming. Control or primed seeds from progeny NILs homozygous for either the Salinas or the UC96US23 alleles at Htg6.1 were tested for germination at high temperatures (Fig. 4). Without priming, the presence of the UC96US23 alleles increased the $T_{50}$ by about $2^{\circ} \mathrm{C}$, consistent with other results for these NILs (Argyris 2008). Surprisingly, NILs with Salinas alleles at Htg6.1 showed a reduced response to priming compared to that of the Salinas parent (compare Figs. 1, 4). The increase in the median temperature for germination by priming in NILs 27 and 86 was negligible, and less that $1^{\circ} \mathrm{C}$ for NIL 2 (Fig. 4). As responses to priming can vary among different seed lots of the same variety dependent upon production environment, storage conditions, and age, responses to priming of the NILs homozygous for the Salinas allele at Htg6.1 might have been enhanced by testing variations in the priming protocol. However, using the same priming conditions, progeny seeds of the same NILs homozygous for the UC96US23 allele exhibited strong responses to priming, 
with increases in their $T_{50}$ values of $2.6,3.1$ and $3.5^{\circ} \mathrm{C}$ for NILs 2, 27, and 86, respectively, compared to the corresponding control seeds (Fig. 4). Primed seeds of NILs containing the UC96US23 allele at Htg6.1 germinated at least $50 \%$ at $33^{\circ} \mathrm{C}$, while seeds of the other genotypes and treatments germinated less than $10 \%$ at that temperature. Statistical analyses conducted using ANOVA confirmed that seeds of all three NILs responded differently to priming depending upon the Htg6.1 allele present $(P<0.0001)$, and that the germination response to the

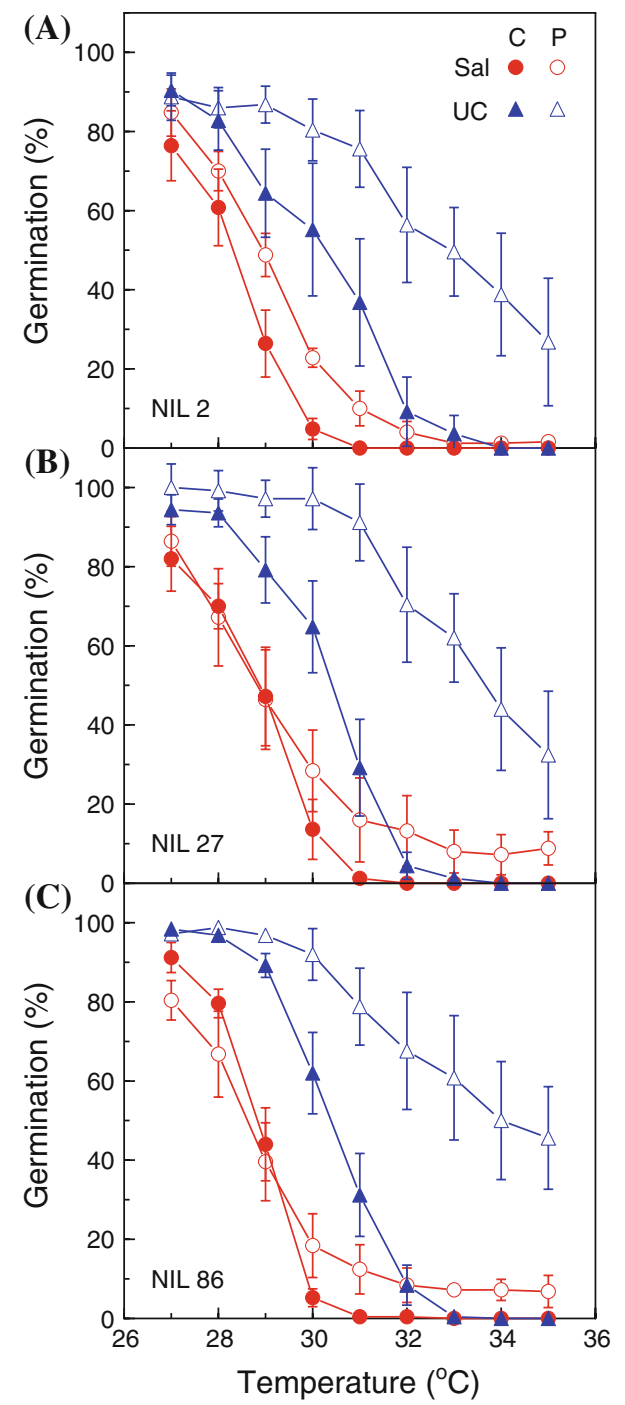

Fig. 4 Sensitivity of germination of control (closed symbols) and primed (open symbols) seeds of near-isogenic lines (NILs) $2(a), 27$ $(b)$, and $86(c)$ in a Salinas background introgressed with a genomic region containing Htg6.1 QTL alleles from Salinas (Sal, circles) or from UC96US23 (UC, triangles). Five $\mathrm{BC}_{3} \mathrm{~S}_{2}$ sub-NILs derived from NILs 2, 27, and 86 homozygous for either Salinas or UC96US23 alleles were assessed for germination at $27-35^{\circ} \mathrm{C}$. Seeds (two replicates of 25 each) were imbibed at each temperature and radicle emergence was scored $48 \mathrm{~h}$ after planting. Pooled standard errors (SE) from the five sub-NILs are plotted as error bars at each temperature treatments (primed or non-primed) across the temperature gradient also depended upon the Htg6.1 allele present $(P<0.0001)$ (Table S3). Although the introgressed region was fairly large due to a limited number of markers available for selection in this region at the time, these similar results in multiple NIL families (in which other remaining UC96US23 loci would be randomized) confirm that the introgressed region containing Htg6.1 strongly influences response to priming.

Priming alters the expression of LsNCED4, LsGA3oxl, and $L s A C S 1$ in seeds imbibed at high temperature

LsNCED4 collocates with Htg6.1, and higher $T_{50}$ values were associated with reduced expression of this gene in seeds imbibed at high temperature (Argyris et al. 2008a). To determine whether priming reduces the expression of LsNCED4 in seeds imbibed at high temperature, mRNA abundance of LsNCED4 was analyzed in the primingresponsive Salinas parent line. Dry control seeds had 3.4fold greater abundance of LsNCED4 mRNA than the dry primed seeds, indicating that LSNCED4 mRNA abundance was reduced during the priming treatment (Fig. 5a), as it is during early imbibition of control seeds (Argyris et al. 2008a). The abundance of LsNCED4 mRNA decreased further in both control and primed seeds after $8 \mathrm{~h}$ of imbibition at $32^{\circ} \mathrm{C}$, then increased significantly (sixfold) only in the control seeds after $24 \mathrm{~h}$ of imbibition. Conversely, dry primed seeds had considerably greater LsGA3oxl and LsACSI mRNA abundance than did the dry control seeds (Fig. 5b, c), indicating that those transcripts accumulated during the priming treatment. After $24 \mathrm{~h}$ of imbibition at $32^{\circ} \mathrm{C}$, abundance of LsGA3oxl and LsACSI mRNAs remained very low or undetectable in the control seeds, but had increased fourfold to fivefold in the primed seeds.

Influence of Htg6.1 allele on expression of LsNCED4, $L s G A 3 o x 1$, and $L s A C S 1$ in response to priming and imbibition temperature

To study how the parental Htg6.1 alleles affected differential gene expression between primed and non-primed seeds, experiments were conducted using seeds of pooled progeny of NILs 27 and 86 homozygous for either the Salinas or UC96US23 alleles at Htg6.1. Preliminary tests determined the $T_{50}$ temperatures for control and primed seeds of each seed pool and germination percentages at 25 and $35^{\circ} \mathrm{C}$ (Table 1 ). Germination was greater than $90 \%$ in all seed lots at $25^{\circ} \mathrm{C}$, whereas only primed seeds germinated at $35^{\circ} \mathrm{C}$, particularly those with the UC96US23 allele. The increase in $T_{50}$ by priming was also greater in NILs carrying the UC96US23 allele at Htg6.1. After $24 \mathrm{~h}$ 


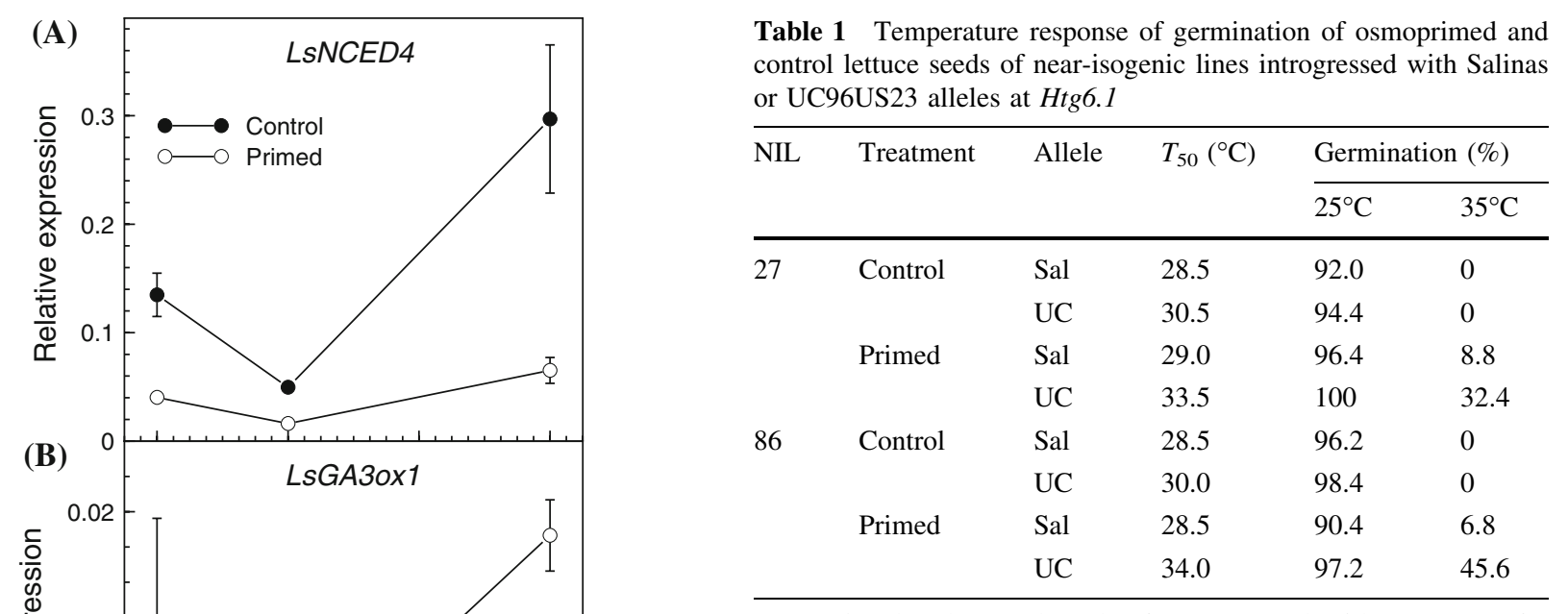

Osmoprimed and control seeds of NILs 27 and 86 homozygous for either Salinas (Sal) or UC96US23 (UC) alleles were imbibed at temperatures between 25 and $35^{\circ} \mathrm{C}$ on a gradient table. Two replicates of 25 seeds each were tested at each temperature and radicle emergence was scored $48 \mathrm{~h}$ after planting. Median maximum germination temperatures $\left(T_{50}\right)$ and mean germination percentages at 25 and $35^{\circ} \mathrm{C}$ are shown

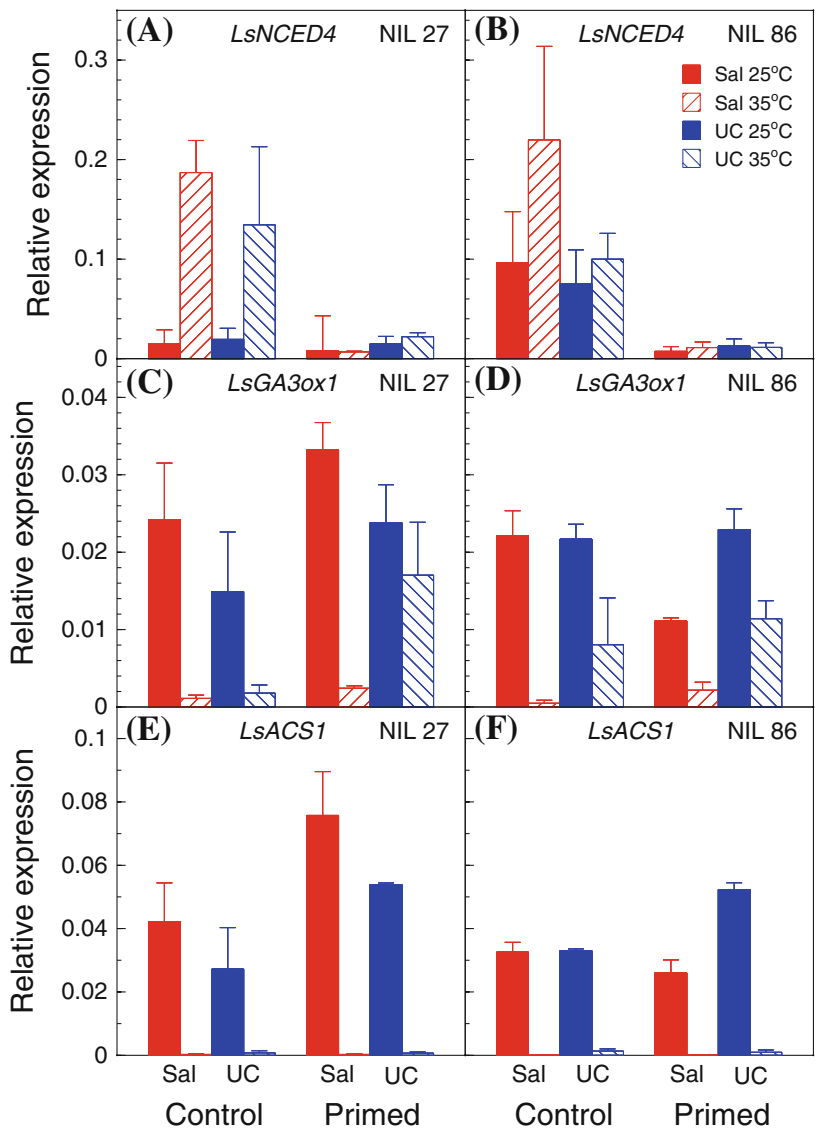

Fig. 6 Expression of LsNCED4 (a,b), LsGA3oxl $(c, d)$ and LsACS1 $(e, f)$ in control and primed seeds of NILs $27(a, c, e)$ and $86(b, c, f)$ introgressed with Salinas (Sal) or UC96US23 (UC) Htg6.1 alleles. Seeds were imbibed at 25 (solid bars) or at $35^{\circ} \mathrm{C}$ (striped bars) for $24 \mathrm{~h}$, then extracted. Twenty seeds of each of five $\mathrm{BC}_{3} \mathrm{~S}_{2}$ sub-NILs were pooled for each Htg6.1 allele and treatment replicate within each NIL lineage. Error bars represent $\pm \mathrm{SE}$ of 3 biological replicates 
expression of LsGA3oxl between the NILs. LsACS1 expression exhibited overall trends similar to that for LsGA3oxl at $25^{\circ} \mathrm{C}$, but LsACS1 expression was almost completely suppressed at $35^{\circ} \mathrm{C}$ in both genotypes regardless of priming treatment (Fig. 6e, f).

Expression of LsNCED4, LsGA3oxl, and LsACSI during and after priming, drying, and imbibition at high temperature

The effects of priming and drying on the expression of LsNCED4, LsGA3oxl, and LsACS1 were studied using seeds of the commercial cultivar Titan, which is closely related genetically to Salinas. Germination of Titan seeds at $35^{\circ} \mathrm{C}$ increased with longer priming durations (Table 2), which corresponded well with declining LsNCED4 mRNA abundance in the primed and dried seeds (Fig. 7a). LsNCED4 mRNA abundance in the dry control seeds was 8.8-fold greater than in the dried 48-h osmoprimed seeds. In contrast, the abundance of LsGA3oxl and LsACSI mRNAs increased with longer priming durations. The dried 48-h osmoprimed seeds had 5.6-fold higher LsGA3oxl mRNA abundance and eightfold greater LsACS1 mRNA abundance than the dry control seeds (Fig. 7b, c). Similar trends were observed for mRNA abundance of these genes in seeds extracted immediately after priming before drying and in hydroprimed seeds (data not shown), indicating that mRNA abundances were not affected significantly by the rapid drying following priming or by the type of priming, respectively.

The consequences of different priming durations on gene expression following imbibition at $35^{\circ} \mathrm{C}$ for $24 \mathrm{~h}$ were also assessed. LsNCED4 mRNA abundance in control seeds and 6 or 12-h primed seeds decreased relative to the levels present before imbibition, but remained higher than in seeds primed for 24 or $48 \mathrm{~h}$ that germinated to higher percentages at $35^{\circ} \mathrm{C}$ (Fig. 7a; Table 2). Conversely, the abundance of LsGA3oxl and LsACS1 mRNAs increased as the priming times increased, particularly in the seeds primed for 24 and $48 \mathrm{~h}$ before imbibition at $35^{\circ} \mathrm{C}$ (Fig. 7b, c).

\section{Discussion}

The regulatory mechanisms controlling germination in lettuce seeds encompass networks that sense external (i.e., light and temperature) and internal (i.e., genetic and physiological) conditions and determine whether germination proceeds to completion or is inhibited prior to radicle emergence. In particular, temperature is a primary factor regulating seed germination in this species (Gonai et al. 2004; Sung et al. 2008). Lettuce seeds exhibit thermoinhibition (fail to germinate) at temperatures well below the biological upper limit for seedling growth (i.e. $>28^{\circ} \mathrm{C}$ ) (Berrie 1966; Gray 1975), and the ability of the seeds to germinate at high temperatures depends on both genetic and environmental factors (Sung et al. 1998; Kozarewa et al. 2006; Argyris et al. 2008a; Contreras et al. 2009). Thermoinhibition in lettuce can delay or prevent germination, resulting in reduced field emergence and stand establishment (Valdes et al. 1985), diminished yield (Cantliffe et al. 1981), and multiple harvests that can reduce quality and profitability (Benjamin 1990). Several plant hormones play key roles in the regulation of thermoinhibition in lettuce seeds (Saini et al. 1986; Cantliffe et al. 2000; Kucera et al. 2005). For example, exposure to ABA can decrease the maximum germination temperature, whereas exposure to GA and ethylene can increase it (Reynolds and Thompson 1973; Saini et al. 1989; Dutta and Bradford 1994; Gonai et al. 2004; Argyris et al. 2008a). Seed priming has been a valuable tool in circumventing thermoinhibition in lettuce seeds due to its ability to increase germination at high temperatures (Heydecker and Coolbear 1977; Cantliffe et al. 1981, 1984; Valdes et al. 1985; Weges 1987).

Table 2 Effect of priming in water (hydropriming) or in polyethylene glycol (PEG) 8000 (osmopriming) for different durations on germination of Titan lettuce seeds at 20 and $35^{\circ} \mathrm{C}$

\begin{tabular}{|c|c|c|c|c|c|c|}
\hline \multirow[t]{3}{*}{ Type of priming } & \multirow[t]{3}{*}{ Imbibition temperature $\left({ }^{\circ} \mathrm{C}\right)$} & \multicolumn{5}{|c|}{ Germination $(\%)$} \\
\hline & & \multicolumn{5}{|c|}{ Priming duration at $9^{\circ} \mathrm{C}(\mathrm{h})$} \\
\hline & & 0 & 6 & 12 & 24 & 48 \\
\hline \multirow[t]{2}{*}{$\mathrm{H}_{2} \mathrm{O}$} & 20 & $98 \pm 1$ & $96 \pm 2$ & $97 \pm 1$ & $96 \pm 2$ & 100 \\
\hline & 35 & 0 & 0 & $12 \pm 2$ & $68 \pm 6$ & $75 \pm 12$ \\
\hline \multirow[t]{2}{*}{ PEG } & 20 & $97 \pm 1$ & $93 \pm 1$ & 100 & 100 & $96 \pm 2$ \\
\hline & 35 & 0 & 0 & $1 \pm 1$ & $40 \pm 4$ & $88 \pm 6$ \\
\hline
\end{tabular}

After priming for the indicated durations at $9^{\circ} \mathrm{C}$, seeds were rapidly dried $\left(2 \mathrm{~h}\right.$ at $32^{\circ} \mathrm{C}$ and $\left.30 \% \mathrm{RH}\right)$ and equilibrated at $9{ }^{\circ} \mathrm{C}$ and $30 \% \mathrm{RH}$ for 2 days. Subsequently, the seeds were imbibed at 20 and $35^{\circ} \mathrm{C}$ and radicle emergence was scored after $48 \mathrm{~h}$. Three replicates of 25 seeds were tested for each treatment; means and standard errors are indicated 
The endosperm envelope surrounding the embryo constitutes a physical barrier to radicle emergence and is required for the imposition of thermoinhibition in lettuce seeds (Borthwick and Robbins 1928; Speer 1974). The rate and extent of weakening of the micropylar endosperm enclosing the radicle tip may be involved in determining whether thermoinhibition occurs (Sung et al. 1998). Sung et al. (2008) recently reported that seed priming reduced the physical resistance of the lettuce endosperm during imbibition by weakening the cell walls and by depleting stored reserves leading to cell collapse prior to radicle emergence. Alternatively, Bradford and Somasco (1994) concluded from experiments comparing intact seeds and excised embryos that the effects of priming in lettuce occurred primarily in the embryo, rather than in the surrounding endosperm tissues, consistent with the proposal by Cantliffe et al. (1984) that priming acted by initiating irreversible embryo expansion. As embryo growth is required to complete germination even if there are structural changes in the endosperm, inhibition of embryo expansion and of endosperm weakening may both be involved in thermoinhibition (Nonogaki et al. 2007). While ABA has long been known to reduce embryo growth capacity (Takeba and Matsubara 1979; Schopfer and Plachy 1984), its effects on endosperm weakening are more variable, with reports of inhibition of weakening in some cases (Toorop et al. 2000; Muller et al. 2006) and others in which relatively little effect was found (Chen and Bradford 2000; Wu et al. 2001). GA, on the other hand, generally promotes both embryo growth and endosperm weakening (Nonogaki et al. 2007).

In order to provide further insight into the causes of lettuce seed thermoinhibition, we investigated the genetic regulation of the effect of seed priming on the temperature sensitivity of germination. We identified a major QTL on chromosome 6 derived from $L$. serriola accession UC96US23 that accounted for $47 \%$ of the variance for the increase in germination at high temperature due to seed priming (Fig. 3). This QTL collocated with a previously identified QTL for high temperature germination ability (Htg6.1) in non-primed seeds of the same RIL population (Argyris et al. 2005, 2008b). Covariate analysis showed a significant QTL associated with priming at this locus even when the effect of the Htg6.1 alleles on basal thermotolerance was removed. This was confirmed with seeds of NILs with Salinas as a recurrent parent that were introgressed with a genomic region containing the UC96US23 allele at this locus, which exhibited both greater high temperature tolerance and an enhanced response to priming (Fig. 4). Thus, the UC96US23 allele at Htg6.1 increases the maximum germination temperature and the response of seeds to priming, suggesting that priming influences the same regulatory mechanisms that control the temperature sensitivity of seed germination.
Both the QTL interval and the introgressed region span hundreds of genes, but considerable evidence points to LsNCED4 as the primary candidate gene. Additional mapping has reduced the Htg6.1 QTL confidence interval to as little as $1 \mathrm{cM}$, and LsNCED4 remains centered in the QTL interval (Argyris et al., unpublished results). Just as reduced expression of the UC96US23 allele of LsNCED4 was associated with high temperature germination capacity (Argyris et al. 2008a), priming also reduced the expression of

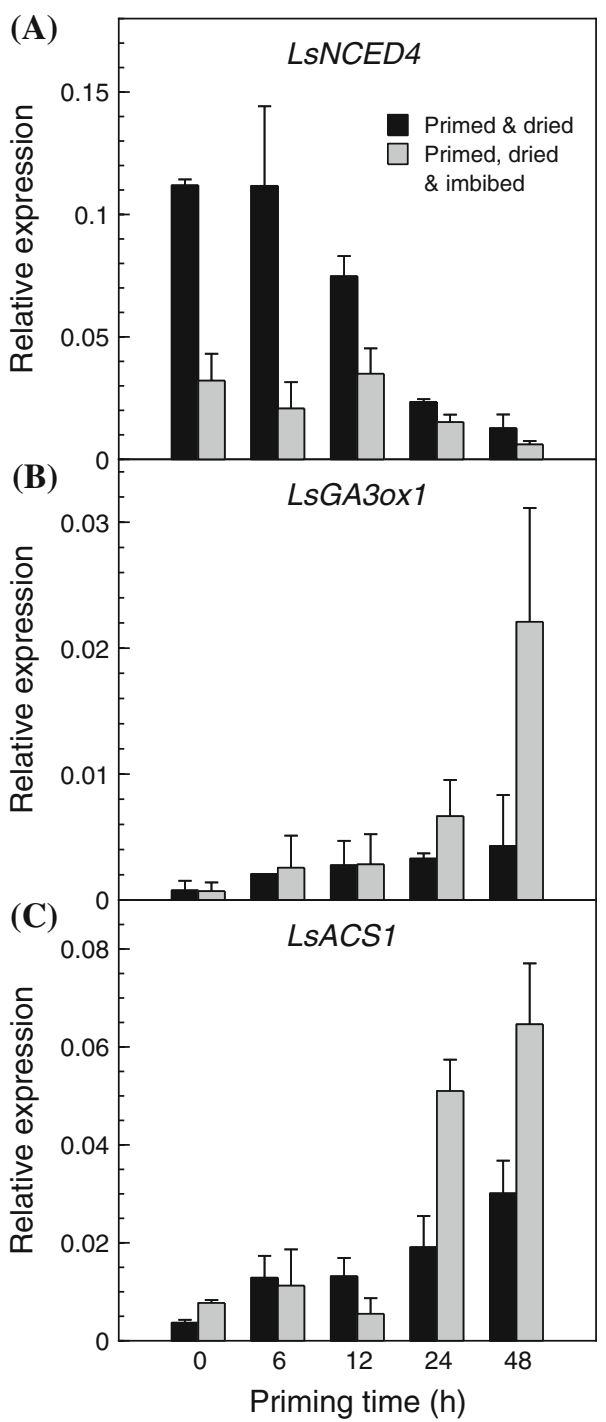

Fig. 7 Expression (mRNA abundance measured by quantitative RT-PCR) of LsNCED4 (a), LsGA3oxl (b), and LsACS1 (c) in Titan lettuce seeds that were primed for 0 (dry control seeds), 6, 12, 24 and $48 \mathrm{~h}$. After osmopriming at $9^{\circ} \mathrm{C}$ in $-1.25 \mathrm{MPa}$ PEG 8000 for the indicated times, the seeds were rinsed, rapidly dried $\left(2 \mathrm{~h}\right.$ at $\left.32^{\circ} \mathrm{C}\right)$, equilibrated at $9^{\circ} \mathrm{C}$ and $30 \% \mathrm{RH}$ for 2 days, and then extracted (black bars). Control and primed seeds were subsequently imbibed in water at $35^{\circ} \mathrm{C}$ for $24 \mathrm{~h}$, and then extracted for gene expression assays (grey bars). Note that the $y$-axes of the panels have different scales. Error bars represent standard error of 3 biological replicates 
LsNCED4 in seeds of Salinas (Fig. 5a), NILs (Fig. 6a, b), and Titan (Fig. 7a), relative to the non-primed seeds of those genotypes imbibed at high temperatures. Thus, priming results in a reduced response of LsNCED4 expression to imbibition at high temperature. As higher expression of LsNCED4 is associated with increased ABA content and inhibition of germination (Argyris et al. 2008a), reduced expression of LsNCED4 following priming likely results in lower ABA content and better germination at high temperatures relative to the non-primed seeds (Fig. 8).

The critical period for induction of thermoinhibition is within the first $8-12 \mathrm{~h}$ of imbibition at high temperature (Argyris et al. 2008a). Imbibition at a lower temperature during priming apparently allows germination processes to progress past this critical point, and subsequent exposure to high temperatures is not able to induce LsNCED4 expression and prevent germination (Figs. 5a, 6a, 6b, 7a). This could be related to the developmental specificity of LsNCED4 expression, which may be restricted to seed development and early imbibition. LsNCED4 is the primary $N C E D$ family member expressed during late seed maturation in lettuce (H. Huo and K.J. Bradford, unpublished results), and the closest homolog of LsNCED4 in Arabidopsis (AtNCED6) exhibits seed-specific expression (Lefebvre et al. 2006; Seo et al. 2006). LsNCED4 mRNA abundance decreased during priming (Fig. 7a) as it does during imbibition in water at permissive temperatures (Argyris et al. 2008a). Thus, priming may allow the seeds to progress past the developmental point at which LSNCED4 can be re-induced by high temperature (Fig. 8). Expression of LsGA3oxl and LsACS1 exhibits the opposite

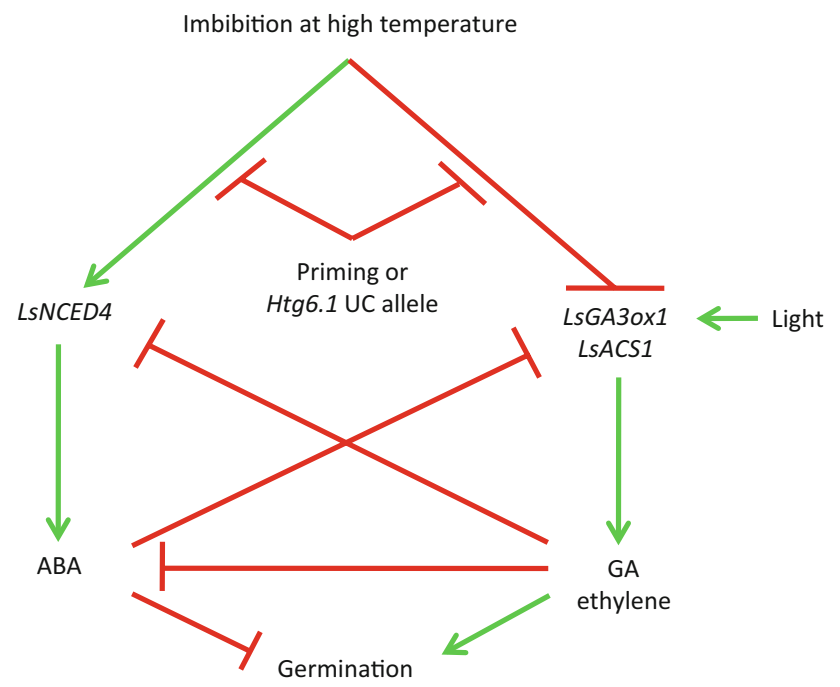

Fig. 8 Proposed model for regulation of thermoinhibition in lettuce seeds and its alleviation by priming. Arrows indicate promotion and bars inhibition of the process or gene expression pattern, as they are not expressed in late seed maturation but are induced during imbibition or priming at low temperature (Fig. 7b, c; Argyris et al. 2008a). Imbibition at high temperature can initially repress expression of both genes (Fig. 6), but not after priming or after the escape time for induction of thermoinhibition (Fig. 8). This suggests that priming acts primarily by allowing the normal events of germination to advance while preventing embryo expansion due to the reduced water potential, rather than by inducing unique regulatory responses.

Reciprocal regulation of expression of ABA versus GA and ethylene biosynthetic genes in lettuce seed germination has been reported (Fig. 8; Gonai et al. 2004; Argyris et al. 2008a; Sawada et al. 2008a, b). The genetic evidence presented here suggests that regulation of LsNCED4 expression and therefore of ABA levels may be a primary temperaturesensing mechanism, at least in these genetic backgrounds, which then triggers subsequent gene expression/repression and metabolic responses in other hormonal pathways. For example, ABA enhances the catabolism of GA and can inhibit the expression of GA biosynthetic genes in Arabidopsis and lettuce seeds (Gonai et al. 2004; Seo et al. 2006; Zentella et al. 2007; Sawada et al. 2008b; Toh et al. 2008). In addition, GA can reciprocally inhibit ABA biosynthesis and promote its catabolism (Oh et al. 2007; Sawada et al. 2008a). Gonai et al. (2004) reported that applications of fluridone (an ABA biosynthesis inhibitor) and GA together decreased the ABA content of lettuce seeds to a sufficiently low level to permit germination at $33^{\circ} \mathrm{C}$ in the dark. GA is required for lettuce seed germination at high temperatures even when ABA biosynthesis is inhibited (Endo et al. 2001; Argyris et al. 2008a). Reduced ethylene production is associated with the inhibition of germination of thermosensitive lettuce genotypes at high temperatures (Nascimento et al. 2000; Kozarewa et al. 2006; Matilla and Matilla-Vazquez 2008). Priming repressed expression of both Salinas and UC96US23 alleles of LsNCED4 in NILs at $35^{\circ} \mathrm{C}$, but expression of LsGA3oxl and LsACSI was still suppressed (either completely or partially) at this temperature (Fig. 6), suggesting that there may be direct effects of temperature on LsGA3oxl and LsACS1 expression (Fig. 8). Previous results suggested that LsGA3oxl and LsACSI might be coordinately regulated (Argyris et al. 2008a); however, while the overall expression patterns are quite similar (Figs. 5, 7), their temperature sensitivities appear to be distinct (Fig. 6). Overall, regulation of the synthesis and action of $\mathrm{ABA}, \mathrm{GA}$ and ethylene is apparently so tightly integrated that environmental influences result in coordinated reciprocal adjustments throughout the regulatory network (Fig. 8; Finch-Savage and Leubner-Metzger 2006; Oh et al. 2007; Finkelstein et al. 2008; Matilla and Matilla-Vazquez 2008).

Light is another major environmental factor influencing seed germination, and there is evidence that light and 
temperature interact through the phytochromes in regulating germination (Heschel et al. 2007). In lettuce seeds, the active phytochrome (Pfr) requirement for germination increases as the temperature increases (Fielding et al. 1992; Kristie and Fielding 1994) and the seeds become more sensitive to inhibition by ABA (Roth-Bejerano et al. 1999; Gonai et al. 2004). Pfr promotes GA biosynthesis (Toyomasu et al. 1998), and light altered both GA responsiveness and GA metabolism in Arabidopsis seeds (Oh et al. 2007). However, GA responsiveness was unaffected by red light treatment of lettuce seeds at $25^{\circ} \mathrm{C}$, indicating that germination was mainly regulated by light via the control of endogenous levels of physiologically active GA (Sawada et al. 2008b). The priming treatments imposed here included exposure to fluorescent (red) light, which likely contributed to the strong response of $L s G A 3 o x l$ expression to priming (Fig. 7). UC96US23 seeds require light for germination, and their thermotolerance is strictly dependent upon light, presumably to promote GA and/or ethylene biosynthesis (Argyris et al. 2008a). GA could substitute for light in promoting germination at high temperature $\left(32^{\circ} \mathrm{C}\right)$ in the dark (Argyris et al. 2008a). Both progression past a developmental window for temperature-dependent LSNCED4 expression and induction of LsGA3oxl and LsACS1 expression by light during priming likely contribute to the priming effect (Fig. 8).

\section{Conclusion}

We have presented evidence that a genetic locus containing the ABA biosynthetic gene LsNCED4 influences the responsiveness of lettuce seeds to priming with respect to the maximum temperature for germination. Introgression of this Htg6.1 locus into a lettuce cultivar increased seed germination at high temperature and enhanced responsiveness to priming, making this treatment even more effective in alleviating thermoinhibition. Reduced expression of LSNCED4 and increased expression of LsGA3oxl and LsACS1 in primed seeds compared to non-primed seeds is associated with the increase in the maximum germination temperature. The expression of these ABA, GA, and ethylene biosynthetic genes could serve as molecular markers to optimize priming treatments. Developmental regulation of gene expression may contribute to the priming effect as the imbibition period allows seeds to progress past a germination checkpoint that is sensitive to thermoinhibition. One challenge for the future will be unraveling whether temperature acts only or primarily through effects on LsNCED4 expression or whether multiple targets independently sense and respond to temperature. Regardless of the primary trigger(s), a complex network of changes in gene expression is associated with germination responses to both priming and temperature, with the fate of germination or dormancy of individual seeds likely being determined by the relative balance between promotive and inhibitory signals.

Acknowledgments Richard Michelmore provided the RIL population, Allen Van Deynze and Richard Michelmore provided the highdensity genetic map, Jason Argyris developed the NILs, Hamid Ashrafi and Maria Truco assisted with the QTL analyses, Peetambar Dahal helped with the quantitative RT-PCR assays, and Anthony Joudi assisted with the germination tests. This work was supported by the Western Regional Seed Physiology Research Group and the U.S. National Science Foundation (grant nos. 0421630 and 0820451 ) through the Compositae Genome Project (http://compgenomics.ucdavis.edu).

Open Access This article is distributed under the terms of the Creative Commons Attribution Noncommercial License which permits any noncommercial use, distribution, and reproduction in any medium, provided the original author(s) and source are credited.

\section{References}

Argyris JM (2008) Natural variation and genetic analyses of seed and seedling traits in lettuce: discovery, confirmation and proposed role for a quantitative trait locus in regulating seed dormancy at high temperature. Ph.D. Thesis, University of California, Davis

Argyris J, Truco MJ, Ochoa O, Knapp SJ, Still DW, Lenssen GM, Schut JW, Michelmore RW, Bradford KJ (2005) Quantitative trait loci associated with seed and seedling traits in Lactuca. Theor Appl Genet 111:1365-1376

Argyris J, Dahal P, Hayashi E, Still DW, Bradford KJ (2008a) Genetic variation for lettuce seed thermoinhibition is associated with temperature-sensitive expression of abscisic acid, gibberellin and ethylene biosynthesis, metabolism and response genes. Plant Physiol 148:926-947

Argyris J, Dahal P, Truco MJ, Ochoa O, Still DW, Michelmore RW, Bradford KJ (2008b) Genetic analysis of lettuce seed thermoinhibition. Acta Hortic 782:23-33

Benjamin LR (1990) Variation in time of seedling emergence within populations: a feature that determines individual growth and development. Adv Agron 44:1-25

Berrie AMM (1966) Effect of temperature and light on germination of lettuce seeds. Physiol Plant 19:429-436

Borthwick HA, Robbins WW (1928) Lettuce seed and its germination. Hilgardia 3:275-305

Bradford KJ, Somasco OA (1994) Water relations of lettuce seed thermoinhibition: I. Priming and endosperm effects on base water potential. Seed Sci Res 4:1-10

Bruggink GT (2004) Update on seed priming: from priming to pregermination, and back. Seed Technol 26:86-91

Cantliffe DJ, Shuler KD, Guedes AC (1981) Overcoming seed thermodormancy in a heat-sensitive romaine lettuce by seed priming. HortScience 16:196-198

Cantliffe DJ, Fischer JM, Nell TA (1984) Mechanism of seed priming in circumventing thermodormancy in lettuce. Plant Physiol 75:290-294

Cantliffe DJ, Sung Y, Nascimento WM (2000) Lettuce seed germination. Hortic Rev 224:229-275

Chen F, Bradford KJ (2000) Expression of an expansin is associated with endosperm weakening during tomato seed germination. Plant Physiol 124:1265-1274

Contreras S, Bennett MA, Metzger JD, Tay D, Nerson H (2009) Red to rar-red ratio during seed development affects lettuce seed germinability and longevity. HortScience 44:130-134 
Cooley MB, Yang H, Dahal P, Mella RA, Downie AB, Haigh AM, Bradford KJ (1999) Vacuolar $\mathrm{H}^{+}$-ATPase is expressed in response to gibberellin during tomato seed germination. Plant Physiol 121:1339-1347

de Castro RD, van Lammeren AAM, Groot SPC, Bino RJ, Hilhorst HWM (2000) Cell division and subsequent radicle protrusion in tomato seeds are inhibited by osmotic stress but DNA synthesis and formation of microtubular cytoskeleton are not. Plant Physiol 122:327-335

Dutta S, Bradford KJ (1994) Water relations of lettuce seed thermoinhibition. II. Ethylene and endosperm effects on base water potential. Seed Sci Res 4:11-18

Dutta S, Bradford KJ, Nevins DJ (1997) Endo-beta-mannanase activity present in cell wall extracts of lettuce endosperm prior to radicle emergence. Plant Physiol 113:155-161

Endo K, Yoshioka T, Gonai T, Satoh S, Hashiba T (2001) Induction of seed germination at high temperatures by herbicides which inhibit carotenoid biosynthesis. Tohoku Weed J 1:3-6

Fielding A, Kristie DN, Dearman P (1992) The temperature of Pfr action governs the upper temperature limit for germination in lettuce. Photochem Photobiol 56:623-627

Finch-Savage WE, Leubner-Metzger G (2006) Seed dormancy and the control of germination. New Phytol 171:501-523

Finkelstein R, Reeves W, Ariizumi T, Steber C (2008) Molecular aspects of seed dormancy. Ann Rev Plant Biol 59:387-415

Gallardo K, Job C, Groot SPC, Puype M, Demol H, Vandekerckhove J, Job D (2001) Proteomic analysis of Arabidopsis seed germination and priming. Plant Physiol 126:835-848

Gao YP, Young L, Bonham-Smith P, Gusta LV (1999) Characterization and expression of plasma and tonoplast membrane aquaporins in primed seed of Brassica napus during germination under stress conditions. Plant Mol Biol 40:635-644

Gonai T, Kawahara S, Tougou M, Satoh S, Hashiba T, Hirai N, Kawaide H, Kamiya Y, Yoshioka T (2004) Abscisic acid in the thermoinhibition of lettuce seed germination and enhancement of its catabolism by gibberellin. J Exp Bot 55:111-118

Gray D (1975) Effects of temperature on the germination and emergence of lettuce (Lactuca sativa L.) varieties. Hortic Sci 50:349-361

Halmer P, Bewley JD, Thorpe TA (1975) Enzyme to break down lettuce endosperm cell wall during gibberellin-induced and lightinduced germination. Nature 258:716-718

Heschel MS, Selby J, Butler C, Whitelam GC, Sharrock RA, Donohue K (2007) A new role for phytochromes in temperature-dependent germination. New Phytol 174:735-741

Heydecker W, Coolbear P (1977) Seed treatments for improving performance-survey and attempted prognosis. Seed Sci Technol 5:353-425

Heydecker W, Higgins J, Gulliver RL (1973) Accelerated germination by osmotic seed treatment. Nature 246:42-44

Job C, Kersulec A, Ravasio L, Chareyre S, Pepin R, Job D (1997) The solubilization of the basic subunit of sugarbeet seed 11-S globulin during priming and early germination. Seed Sci Res 7:225-243

Kozarewa I, Cantliffe DJ, Nagata RT, Stoffella PJ (2006) High maturation temperature of lettuce seeds during development increased ethylene production and germination at elevated temperatures. J Am Soc Hortic Sci 131:564-570

Kristie DN, Fielding A (1994) Influence of temperature on the Pfr level required for germination in lettuce cv. Grand Rapids. Seed Sci Res 4:19-25

Kucera B, Cohn MA, Leubner-Metzger G (2005) Plant hormone interactions during seed dormancy release and germination. Seed Sci Res 15:281-307

Lefebvre V, North H, Frey A, Sotta B, Seo M, Okamoto M, Nambara E, Marion-Poll A (2006) Functional analysis of Arabidopsis
NCED6 and NCED9 genes indicates that ABA synthesised in the endosperm is involved in the induction of seed dormancy. Plant $\mathbf{J}$ 45:309-319

Ligterink W, Kodde J, Lammers M, de Maagd R, Hilhorst H (2007) Molecular dissection of seed priming. Translational seed biology: from model systems to crop improvement, Davis, CA. http://www.plantsciences.ucdavis.edu/Symposium/2007/

Matilla AJ, Matilla-Vazquez MA (2008) Involvement of ethylene in seed physiology. Plant Sci 175:87-97

McDonald MB (2000) Seed priming. In: Black M, Bewley JD (eds) Seed technology and its biological basis. Sheffield Academic Press, Sheffield, pp 287-325

Müller K, Tintelnot S, Leubner-Metzger G (2006) Endosperm-limited Brassicaceae seed germination: abscisic acid inhibits embryoinduced endosperm weakening of Lepidium sativum (cress) and endosperm rupture of cress and Arabidopsis thaliana. Plant Cell Physiol 47:864-877

Nascimento WM, Cantliffe DJ, Huber DJ (2000) Thermotolerance in lettuce seeds: association with ethylene and endo-beta-mannanase. J Am Soc Hortic Sci 125:518-524

Nascimento WM, Cantliffe DJ, Huber DJ (2001) Endo-beta-mannanase activity and seed germination of thermosensitive and thermotolerant lettuce genotypes in response to seed priming. Seed Sci Res 11:255-264

Nonogaki H, Morohashi Y (1999) Temporal and spatial pattern of the development of endo-beta-mannanase activity in germinating and germinated lettuce seeds. J Exp Bot 50:1307-1313

Nonogaki H, Chen F, Bradford KJ (2007) Mechanisms and genes involved in germination sensu stricto. In: Bradford KJ, Nonogaki $\mathrm{H}$ (eds) Seed development, dormancy and germination. Blackwell Publishing, Oxford, pp 264-304

Oh E, Yamaguchi S, Hu JH, Yusuke J, Jung B, Paik I, Lee HS, Sun TP, Kamiya Y, Choi G (2007) PIL5, a phytochrome-interacting bHLH protein, regulates gibberellin responsiveness by binding directly to the GAI and RGA promoters in Arabidopsis seeds. Plant Cell 19:1192-1208

Reynolds T, Thompson PA (1973) Effects of kinetin, gibberellins and $( \pm)$ abscisic acid on the germination of lettuce (Lactuca sativa). Physiol Plant 28:516-522

Roth-Bejerano N, Sedee NJA, van der Meulen RM, Wang M (1999) The role of abscisic acid in germination of light-sensitive and light-insensitive lettuce seeds. Seed Sci Res 9:129-134

Saini H, Consolacion E, Bassi P, Spencer M (1986) Requirement for ethylene synthesis and action during relief of thermoinhibition of lettuce seed germination by combinations of gibberellic acid, kinetin, and carbon dioxide. Plant Physiol 81:950-953

Saini HS, Consolacion ED, Bassi PK, Spencer MS (1989) Control processes in the induction and relief of thermoinhibition of lettuce seed germination: actions of phytochrome and endogenous ethylene. Plant Physiol 90:311-315

Sawada Y, Aoki M, Nakaminami K, Mitsuhashi W, Tatematsu K, Kushiro T, Koshiba T, Kamiya Y, Inoue Y, Nambara E, Toyomasu T (2008a) Phytochrome- and gibberellin-mediated regulation of abscisic acid metabolism during germination of photoblastic lettuce seeds. Plant Physiol 146:1386-1396

Sawada Y, Katsumata T, Kitamura J, Kawaide H, Nakajima M, Asami T, Nakaminami K, Kurahashi T, Mitsuhashi W, Inoue Y, Toyomasu T (2008b) Germination of photoblastic lettuce seeds is regulated via the control of endogenous physiologically active gibberellin content, rather than of gibberellin responsiveness. J Exp Bot 59:3383-3393

Schopfer P, Plachy C (1984) Control of seed germination by abscisic acid. 2. Effect on embryo water uptake in Brassica napus L. Plant Physiol 76:155-160

Seo M, Hanada A, Kuwahara A, Endo A, Okamoto M, Yamauchi Y, North H, Marion-Poll A, Sun T-p, Koshiba T, Kamiya Y, 
Yamaguchi S, Nambara E (2006) Regulation of hormone metabolism in Arabidopsis seeds: phytochrome regulation of abscisic acid metabolism and abscisic acid regulation of gibberellin metabolism. Plant J 48:354-366

Soeda Y, Konings M, Vorst O, van Houwelingen A, Stoopen GM, Maliepaard CA, Kodde J, Bino RJ, Groot SPC, van der Geest AHM (2005) Gene expression programs during Brassica oleracea seed maturation, osmopriming, and germination are indicators of progression of the germination process and the stress tolerance level. Plant Physiol 137:354-368

Speer HL (1974) Some aspects of function of endosperm during germination of lettuce seeds. Can J Bot 52:1117-1121

Stam P (1995) JoinMap 2.0 deals with all types of plant mapping populations. Plant genome III abstracts. http://www.intl-pag.org/ 3/abstracts/47pg3.html

Sung Y, Cantliffe DJ, Nagata R (1998) Using a puncture test to identify the role of seed coverings on thermotolerant lettuce seed germination. J Am Soc Hortic Sci 123:1102-1106

Sung Y, Cantliffe DJ, Nagata RT, Nascimento WM (2008) Structural changes in lettuce seed during germination at high temperature altered by genotype, seed maturation temperature, and seed priming. J Am Soc Hortic Sci 133:300-311

Takeba G, Matsubara S (1979) Measurement of the growth potential of the embryo in New York lettuce seed under various combinations of temperature, red light and hormones. Plant Cell Physiol 20:51-61

Tan BC, Joseph LM, Deng WT, Liu LJ, Li QB, Cline K, McCarty DR (2003) Molecular characterization of the Arabidopsis 9-cis epoxycarotenoid dioxygenase gene family. Plant J 35:44-56

Tarquis AM, Bradford KJ (1992) Prehydration and priming treatments that advance germination also increase the rate of deterioration of lettuce seeds. J Exp Bot 43:307-317

Toh S, Imamura A, Watanabe A, Nakabayashi K, Okamoto M, Jikumaru Y, Hanada A, Aso Y, Ishiyama K, Tamura N, Iuchi S, Kobayashi M, Yamaguchi S, Kamiya Y, Nambara E, Kawakami N (2008) High temperature-induced abscisic acid biosynthesis and its role in the inhibition of gibberellin action in Arabidopsis seeds. Plant Physiol 146:1368-1385

Toorop PE, van Aelst AC, Hilhorst HWM (2000) The second step of the biphasic endosperm cap weakening that mediates tomato (Lycopersicon esculentum) seed germination is under control of ABA. J Exp Bot 51:1371-1379

Toyomasu T, Kawaide H, Mitsuhashi W, Inoue Y, Kamiya Y (1998) Phytochrome regulates gibberellin biosynthesis during germination of photoblastic lettuce seeds. Plant Physiol 118:1517-1523

Truco MJ, Antonise R, Lavelle D, Ochoa O, Kozik A, Witsenboer H, Fort SB, Jeuken MJW, Kesseli RV, Lindhout P, Michelmore RW, Peleman J (2007) A high-density, integrated genetic linkage map of lettuce (Lactuca spp.). Theor Appl Genet 115:735-746

Valdes VM, Bradford KJ, Mayberry KS (1985) Alleviation of thermodormancy in coated lettuce seeds by seed priming. HortScience 20:1112-1114

van Leeuwen H, Caldwell DG, Stoffel K, Chen F, Kozik A, Truco MJ, Michelmore RW, Van Deynze AE (2007) GeneChip for massively parallel genotyping and gene expression analysis. Plant and Animal Genome XV, San Diego

van Leeuwen H, Stoffel K, Kozik A, Cui X, Ashrafi H, McHale L, Lavelle D, Wong G, Chen F, Truco MJ, Van Deynze A, Michelmore RW (2009) High-density mapping of the lettuce genome with SFP markers in over 15,000 unigenes. In Plant and Animal Genome XVII, San Diego, CA

Weges R (1987) Physiological analysis of methods to relieve dormancy of lettuce seeds. Ph.D. Thesis, Agricultural University, Wageningen, The Netherlands

Wu CT, Leubner-Metzger G, Meins F, Bradford KJ (2001) Class I beta-1,3-glucanase and chitinase are expressed in the micropylar endosperm of tomato seeds prior to radicle emergence. Plant Physiol 126:1299-1313

Zentella R, Zhang ZL, Park M, Thomas SG, Endo A, Murase K, Fleet CM, Jikumaru Y, Nambara E, Kamiya Y, Sun TP (2007) Global analysis of DELLA direct targets in early gibberellin signaling in Arabidopsis. Plant Cell 19:3037-3057 